\title{
A Direct Relining Method Using a Tissue Conditioner as the Spacer
}

\author{
Maeda Yoshinobu, DDS, PhD, Sogo Motofumi, DDS, PhD, \\ Tsugawa Tsuyoshi, DDS and Yamamoto Hideki, DDS \\ Division for Interdisciplinary Dentistry, Osaka University School of Dentistry \\ (Chief : Prof. Maeda Yoshinobu)
}

\section{Clinical significance}

Using a tissue conditioner prior to direct relining, the operator can confirm the necessary location and thickness of the relining material as well as minimize patient discomfort and laboratory time, particularly for distal free-end denture bases.

\section{ABSTRACT}

Purpose: This report describes a direct relining method using tissue conditioning material as the spacer.

Materials and Methods: Tissue conditioning material is applied to the denture base at the first visit, and the occlusion is adjusted. When the patient returns for the second visit, the denture base fit, function, and patient comfort are reexamined. The location of the tissue stoppers is determined to maintain the space for the relining material ; possibilities for these tissue stoppers are the rests on the anterior abutments as well as the distal end area of the distal extension base. The tissue conditioning material is removed from the denture base except for the distal end stopper areas. The denture base surface is ground to expose the non-contaminated resin surface and the relining surface is treated with a primer for relining resin. The mixed new resin material is applied to the denture base, and then the denture is returned to the patient's mouth and pressed down with the operator's fingers at the most stable position until the initial curing stage. The remaining spacer area is removed and the abovementioned procedure is repeated.

Discussion: Although the indirect method is predictable and precise, this approach requires a certain amount of lab procedure time and a relining device. Also there are some situations in which a direct relining method such as that described in this report is preferable, especially for removable partial dentures.

Conclusion: By utilizing tissue conditioner material as the stopper during the procedure, simple direct relining of removable partial dentures is possible.

\section{Key words}

direct method, reline, tissue conditioner, spacer, distal extension

Corresponding author: Maeda Yoshinobu

1-8, Yamadaoka, Suita, Osaka 565-0871, Japan

Tel : +81-6-6879-2386, Fax : +81-6-6879-2387

E-mail : ymaeda@dent.osaka-u.ac.jp

Received on March 24, 2005/Accepted on May 24, 2005 


\section{INTRODUCTION}

The accuracy of fit of the denture base on the mucosa using a method such as the altered cast technique ${ }^{1,2)}$ is essential for properly distributing the functional load over the supporting bone structure. The long-term use of removable dentures, however, causes changes in the supporting tissue due to the underlying bone resorption $^{3-5)}$. Since the misfit of the denture base to edentulous mucosa causes further bone loss and excessive loading on the abutment teeth, adjustments and correction are required.

Although the indirect method is predictable and precise ${ }^{6-8)}$, there are some clinical situations in which a direct relining method $^{9,10)}$ is preferable, especially for removable partial dentures. The critical factor in the direct relining method is positioning of the denture base relative to the edentulous mucosa in distal free end situations. This report describes a simple direct relining method utilizing a tissue conditioner as the spacer.

\section{MATERIALS AND METHODS}

1. Examine the fit of the denture base on the supporting mucosa using silicone material (Fit-checker, GC, Tokyo, Japan) or pressure indicating paste (Mizzy Inc., Cherry Hill, NJ, USA).

2. Grind off the mucosal surface of the denture base to be relined using a carbide bur (Komet H 79 SGE-070, Brasseler GmbH \& Co. KG, Lemgo, Germany) to make space for the tissue conditioner.

3. Apply tissue conditioning material to the denture base (Tissue conditioner, Shofu, Kyoto, Japan), adjust the occlusion using articulating paper, and then dismiss the patient (Fig. 1).

4. Reexamine the denture base fit, along

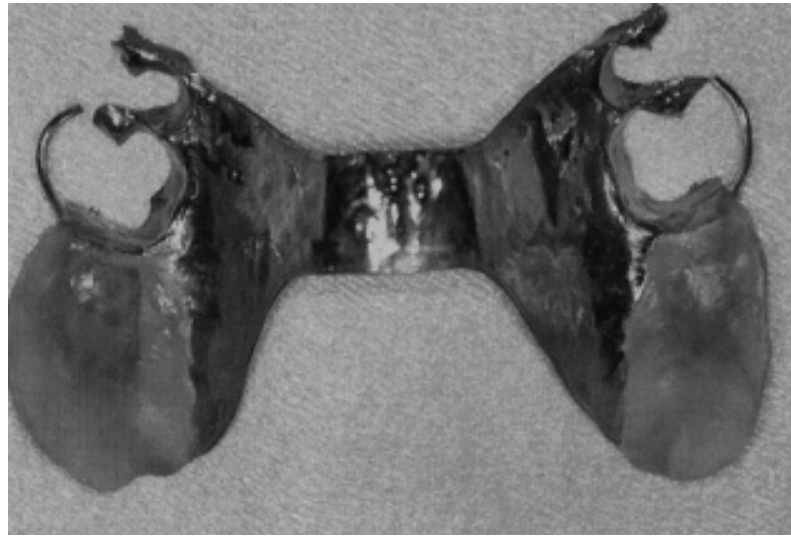

Fig. 1 Apply tissue conditioning material to denture base

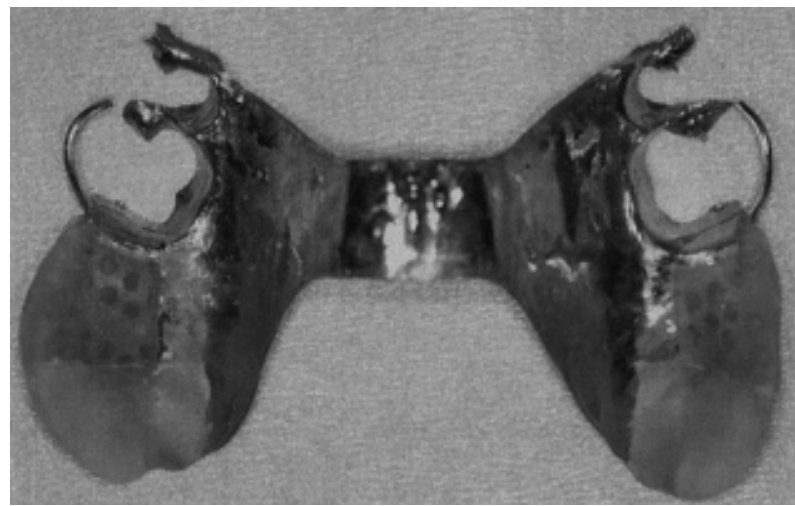

Fig. 2 Remove tissue conditioning material from denture base except for distal end stopper areas

with function and patient comfort, when the patient returns for the second visit.

5. Determine the location of the tissue stoppers to hold the space for the relining material. For distal extensions, the rests on the anterior abutments are possibilities, as well as the area at the distal end of the distal extension base.

6. Remove the tissue conditioning material from the denture base except for the distal end stopper areas. Grind off the denture base surface to expose the non-contaminated resin surface (Fig. 2). Form a bevel at the denture border to accommodate the new relining material and to form a smooth transition (Fig. 3)

7. Treat the relining surface with a primer of relining resin (Denture liner adhesive agent, 


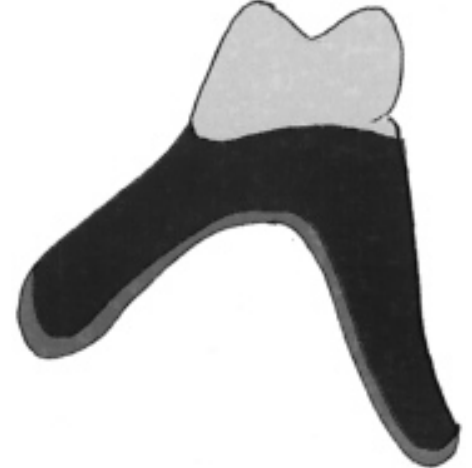

Fig. 3 Form bevel at denture border to accommodate new relining material

Shofu) to enhance the adhesion of the new relining resin material to the existing resin or metal material. The metal denture base surface area, as well as the adhesive resin primer, is sandblasted.

8. Mix the powder and liquid of the relining resin material (Denture liner, Shofu) at the appropriate ratio and remove any air bubbles on a glass plate.

9. Apply the mixed new resin material to the denture base, return the denture to the patient's mouth and press down at the most stable position with the operator's fingers until the initial curing stage. Then ask the patient to maintain the intercuspal position until the material completely sets. At this time, the precise adaptation of the anterior rests is carefully examined. Material overflowing into the undercut area should be removed with a sharp instrument.

10. Remove the denture from the patient's mouth after 5 minutes and place in lukewarm water with resin hardening agents (Denture liner hardener, Shofu).

11. Remove the tissue conditioner from the distal end stopper areas (Fig. 4).

12. Repeat steps 7 to 10 above as needed.

13. Trim the excessive relining material and adjust the occlusion ${ }^{11}$.

14. Polish and finish the denture, especially

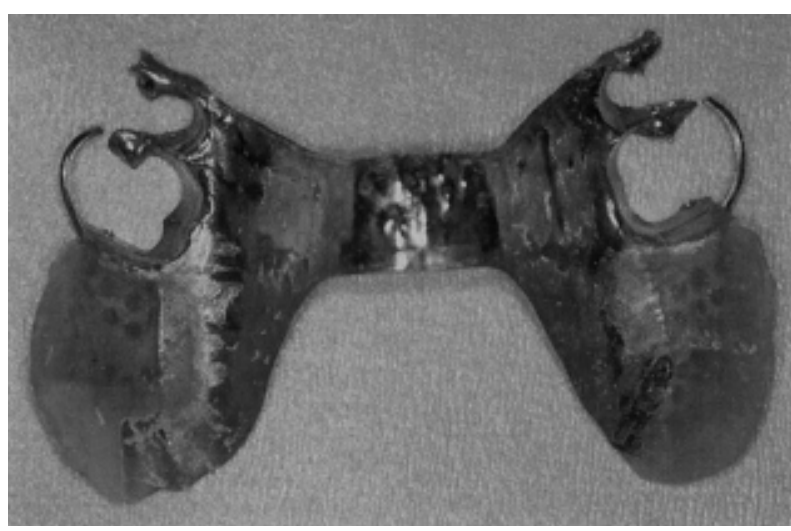

Fig. 4 Remove tissue conditioner from distal end stopper areas

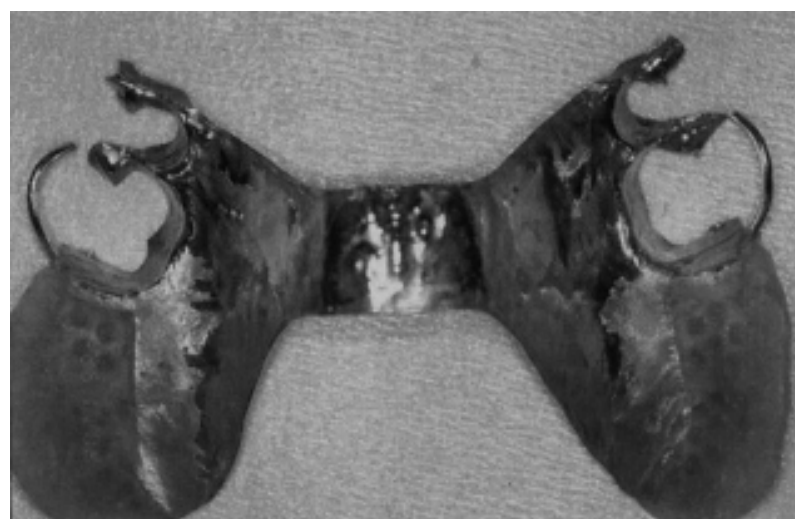

Fig. 5 Polish and finish denture, especially around denture border area

around the denture border area (Fig. 5).

\section{Difference from the Conventional Method}

To reestablish the appropriate fit of the denture base to the edentulous mucosa, tissue conditioning material is often applied before the relining procedure. There are two methods of relining removable dentures, namely, the direct and indirect methods. Although indirect methods are predictable and precise, these approaches require a certain amount of lab procedure time and a relining device ${ }^{12}$. Also there are some situations where a direct relining method is preferable, especially for removable partial dentures. 


\section{Effect on Performance}

Advantages of the method described in this article are:(1) decrease of the lab procedure time and cost, (2) maintenance of space for the relining material during the procedure, and (3) minimization of the vertical height alteration. This method can be applied not only to removable partial dentures but also to complete dentures or overdentures by leaving the tissue conditioner stopper area in the appropriate location in the arch in both the anterior and posterior regions.

Possible disadvantages of this method are: (1) prolonged chair time, (2) overlapping of the material at the second step due to the difference in denture positioning, and (3) precise reconstruction of the border morphology created by the tissue conditioner cannot be expected. It is better for the operator to hold the denture throughout the procedure instead of asking the patient to hold it in the intercuspal position in order to minimize the second problem.

\section{CONCLUSION}

By utilizing tissue conditioner material as the stopper during the procedure, simple direct relining of removable partial dentures is possible.

\section{REFERENCES}

1) Leupold RJ, Flinton RJ, Pfeifer DL. Comparison of vertical movement occurring during loading of distal-extension removable partial denture bases made by three impression techniques. J Prosthet Dent 68:290-293, 1992.

2) Shifman A. Index to reposition the metal framework accurately on the altered cast. J Prosthet Dent 68 : 979-981, 1992.

3) Atwood DA. Reduction of residual ridges: a major oral disease entity. J Prosthet Dent 26:266-279, 1971.

4) Crum RJ, Rooney GE Jr. Alveolar bone loss in overdentures : a 5-year study. J Prosthet Dent 40 : 610-613, 1978 .

5) Kalk W, de Baat C. Some factors connected with alveolar bone resorption. J Dent 17 : 162-165, 1989.

6) Renner PR, Boucher LJ. Removable partial dentures. 359-389, Chicago : Quintessence Publishing Co., Inc, 1987.

7) Breeding LC, Dixon DL, Lund PS. Dimensional changes of processed denture bases after relining with three resins. J Prosthet Dent 66 : 650-656, 1991.

8) Massad JJ, Cagna DR. Relining extension-base removable partial dentures. Compend Contin Educ Dent $23: 24-29,2002$.

9) Matsumura $\mathrm{H}$, Tanoue N, Kawasaki et al. Clinical evaluation of a chemically cured hard denture relining material. J Oral Rehabil 28:640-644, 2001

10) Haywood J, Basker RM, Watson CJ et al. A comparison of three hard chairside denture reline materials. Part I. Clinical evaluation. Eur J Prosthodont Restor Dent 11:157-163, 2003.

11) Maeda Y, Wood W. Finite element method for the simulation of bone resorption beneath complete denture. J Dent Res 68：1370-1373, 1989.

12) Plummer KD, Hall GB. Simplifying the use of a reline jig. J Prosthet Dent 91:399-400, 2004. 